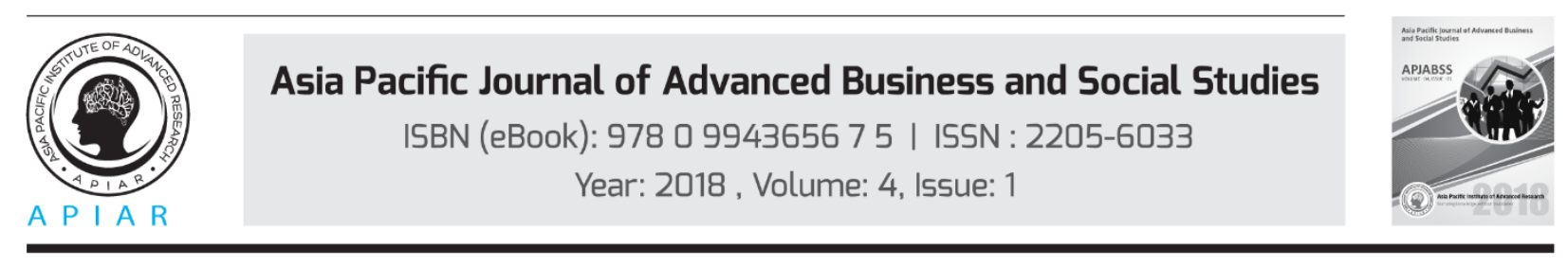

\title{
UNDERSTANDING ORGANISATIONAL DISPUTES: MOVING BEYOND PERSONAL ACCOUNTS
}

\author{
Dr Princess Habiba \\ Griffith University, Brisbane, Australia \\ Email: pchabiba@hotmail.com
}

\begin{abstract}
Organisational conflicts, such as workplace bullying and sexual harassment, represent an area of deep concern for organisations on a Global scale. The primary aim of most organisations is to minimise any such conflicts through containment measures that keep the issues in-house. Since the 1930s, several workplace changes have contributed to a tightening-up of containment measures through an emphasis on individuals and individual responsibility in organisations. However, this over emphasis on the interpersonal aspects of a conflict can deflect attention from other factors that play a role and can result in the issue escalating and/or re-emerging and causing ongoing and potentially costly problems. A sociological analysis of public cases of organisational conflict, using Luc Boltanski's affair model (process) and Pierre Bourdieu's field theory (power relations) has revealed that factors, such as prior histories and the affiliations used by the protagonists to defend their position, are often overlooked. Not only can this contribute to the re-emergence of the problem/s, but may also result in the conflict becoming a public affair. The case of Brodie Panlock, a young Victorian woman who committed suicide after being subjected to workplace bullying(2006) and the sexual harassment case of Kristy FraserKirk, a junior publicist for David Jones, who claimed she was sexually harassed by the CEO Mark McInnes (2010), are both examined here to highlight some of these factors. To address organisational conflict effectively, the focus must move beyond personal accounts and superficial measures, which focus on protagonists to explore all contributing factors.
\end{abstract}

Keywords: Organisational Disputes, Interpersonal Aspects, Luc Boltanski's Affair Model, Pierre Bourdieu's Field Theory.

\section{Workplace changes and the emergence of categories of organisational conflict: A psychological focus}

Since the 1980s, many new categories of organisational conflict, such as workplace bullying and sexual harassment, have emerged and become areas of concern for all stakeholders (e.g. organisational players, the protagonists, collective groups - union, legal and government players and the wider public) (Habiba, 2014). Over the decades, particularly from the 1930s on, conditions in organisations have steadily changed in response to the economic pressures arising from the globalisation of work(Habiba, 2014, 2016; Harvey, 1990).

Analysis of workplace literature from the 1930s to the current time, has shown that there were several key changes to workplace cultures, which increasingly shift attention from workers as part of a collective to workers as individuals. Key changes have included changes to work modes from permanent or full-time agreements to flexible modes and the casualisation of work agreements (Harvey, 1990), the introduction of human resource (HR) officers, new 
Occupational Health and Safety (OHS) laws, the alienation of unions and the introduction of neoliberal policies. These changes arose in response to the economic pressures and changes to technology, which meant organisations had to find new ways of operating on a global scale (Habiba, 2014; Harvey, 1990).

In keeping with these demands, new management procedures were evolving. One of the key changes to managerial styles that humanised relations and focused attention on individuals and their personal responsibility in the workplace, was the introduction of HR officers in the 1960s, whose primary role was to negotiate the conditions of employment between the employer and employees (Ehrlich, 1997; Khilawala, 2011). A key part of this role was (and still is) to develop a bond with employees to enhance loyalty to the organisation and to facilitate internal processes for managing the relationship, including in the event of conflict (Habiba, 2014; Khilawala, 2011). This was critical to the containment of arising issues, as it shifted the onus of responsibility on to the individuals, central to the conflict (Habiba, 2014). This relationship was strengthened further through the destabilisation of unionism, which had the effect of isolating employees, therefore, putting more pressure on them to negotiate their own workplace agreements (particularly from the 1950s on)(Habiba, 2014; Harvey, 1990; Lécuyer, 2003). The introduction of new OHS laws during the 1970s (Engman, 2003; Eurofound, 2009), emphasised the psychological aspects of workplace relations, whilst the introduction of neoliberal policies (1970s-1980s), as a means of dealing with growing economic pressures, further exacerbated the destabilisation of workers' positions (Bourdieu, 1998; George, 1999; Habiba, 2014; Harvey, 2005).

As a result of these changes, the focus on individuals in the workplace and their personal responsibility increased. As employers, employees and other stakeholders have come to understand these changes, they have had to adjust the ways in which they relate to one another. This has created many stressors for all players as these new ways of operating are negotiated. One of the key concerns has been containing these conflicts to prevent them from escalating into the public domain where the negotiation processes come under public scrutiny. Containment, in the context of this work, refers specifically to the measures employed by stakeholders to prevent an escalation of the conflict and to minimise the negative consequences that may arise from escalation (Habiba, 2013a, 2014, 2016).

With the emphasis shifting to more individualistic and psychologised views of workplace relations, the conditions leading up to the 1980 s were perfect for new categories of organisational conflict, such as workplace bullying and sexual harassment, to take shape and emerge (Habiba, 2014). This is supported by a further analysis of workplace bullying literature, as an example of organisational conflict, using Hacking's (1986, 2006) search engines for exploring the emergence of such categories. As a category emerges, it moves through each "engine" and gains legitimacy over a considerable period of time. Hacking (1986) describes how a category is established and gains a place in our culture. He explains that categories evolve through a desire to control and/or help groups of people. However, the risk with creating definitions/parameters around the category is that the target groups can be changed through their engagement with the categorisation. That is, as people identify with the new descriptors they may begin to 'line up' behind the category and change accordingly (Hacking, 1986, p.222).

There are 10 stages to Hacking's model (Hacking, 1986, 2006). Stages 1-7 are "engines of discovery for fact finding and making up people"(Hacking, 2006, para. 1). The last three bring the category into full being:8 is an engine of practice; 9 , an engine of administration; and 1ois an engine of resistance and reclamation over the category (Hacking, 2006, para. 23).

Two additional stages were added (see Habiba, 2014) to highlight features taken from the analysis of workplace changes (highlighted in bold): 
Trigger- what started the interest in the phenomenon;

1. Count - determining prevalence;

2. Quantify - determining how far the problem extends;

3. Create norms - this includes identifying the "norms" for the phenomenon and deviance from them;

4. Correlate - make links between possible causes;

5. Medicalise - this allows for treatment;

6. Biologise - are there any biological causes that may be contributing to/causing the problem? (e.g. chemical imbalance);

7. Geneticise - can genetic factors be blamed;

8. Normalise - treatments are shown to have an effect;

Legislate - changes to legislation occurring in line with the emergence of the category (e.g. OHS laws);

9. Bureaucratise - responses to the category (services) using administration (government) and;

10. Resist and reclaim - those who have become categorised establish attempt to control the ways in which they are described (Habiba, 2014).

The analysis of workplace bullying literature revealed that as the category developed, its progression slowed down in the later search engines and as such, the category was still emerging. Further, the emphasis on the protagonists as central to the issue, for example through the medicalisation, normalisation (treatment of the individuals) and intervention measures which focus on the protagonists (bureaucracy), has contributed the category's own containment as it deflects attention from other possible contributory factors (Habiba, 2014, p. 74).

\section{Moving to include broader explanations: A sociological approach}

In order to expand the possibilities for better and more lasting resolutions, it is necessary to broaden the scope of analysis to include other approaches that go beyond those that are tied to personal/psychologised explanations. Here, two public cases of organisational conflict were examined using a sociological approach. Boltanski's affair model (1996) was used to explore conflict escalation as a process and then Bourdieu's field theory (Bourdieu, 2004; Bourdieu \& Wacquant, 1992) was used to expand upon details gleaned through the Boltanski analysis.

\section{A brief overview of the cases}

Two cases are used to highlight some of the key points in a broader analysis. Brodie Panlock was a young woman who committed suicide after being bullied in her workplace, Café Vamp, Victoria (2005). This case went on to become a full-blown public trial of the events that led to her death, placing a spotlight on other factors that played a role in her death. This resulted in changes to law in Victoria and to workplace culture (Adonis, 2010). Whereas, in the David Jones (DJs) case, Kristy-Fraser Kirk made the claim in 2010 that the CEO, Mark McInnes, had sexually harassed her(Fife-Yeomans, 2010b; Huntington, 2010a). Whilst this case escalated into the public domain, it was eventually recontained through a private settlement between FraserKirk, McInnes and David Jones (Jones, 2010). The measures used to address the issue did not go beyond the relations between the protagonists and as such, the changes made to deal with future issues of the same nature were superficial and internalised, making them hard to examine in any detail (Habiba, 2013b, 2014). As a result, the risk of new claims being made and the issue 
re-emerging cannot be discounted. Both cases were compared using Boltanski's (1996) affair model (process) and Bourdieu's (Bourdieu, 2004; Bourdieu \& Wacquant, 1992) field theory.

\section{Explaining the escalation of conflict using Boltanski's affair model}

It is important to understand how a conflict escalates and what measures are used to contain it. Containment is critical to prevent the conflict escalating and potentially affecting productivity and staffing (e.g. players may take leave, resign or be removed), which can be an expensive enterprise (Hoel, Sheehan, Cooper, \& Einarsen, 2011). However, if the conflict escalates into the public domain, the fall out may result in serious reputational damage and larger, ongoing financial penalties (e.g. legal costs, fines and compensation payments) (Boltanski, 1996).

Boltanski identifies four phases that a conflict may pass through as it escalates: 1. onset, 2. breach of containment, 3. recontainment and 4. social affair (1996; Habiba, 2016). The first three phases are psychological in nature, that is, they focus on those central to the conflict and psychologised approaches, as a means of containment. Most organisational conflicts, such as workplace bullying, are dealt with as psychological affairs. This deflects attention from other factors that may have contributed to the conflict. Further, it results in superficial resolutions e.g. changes to staff and/or policies, which can result in the issues continuing for extended periods, re-emerging later or in new forms (new players/locations) and/or escalating into the public domain (Habiba, 2013a).If the conflict breaches containment, the emphasis is on recontaining it through private agreements. However, the risks remain the same as for a conflict contained during the onset phase (ongoing problems, re-emergence etc.). For a conflict to become a social affair, there must be a shift from the personal/psychologised position to a depersonalised and generalised approach. This requires the help of a collective, such as union or government players to transform the affair as a matter of general concern (Boltanski, 1996). The affair cannot be recontained at this point and results in significant changes, including to systemic structures, law and /or culture (Boltanski, 1996; Habiba, 2013a).

Boltanski (1996)explains that each phase can be made up of numerous events. Each event is defined by: a denunciation which causes the positions in the event to be filled- e.g. target, persecutor, judge; the identification of the protagonists (identities remain anonymous during onset); claims made by each side to defend their position, which includes the use of resources (affiliations with others and other proofs, such as physical evidence -emails, photographs, etc.) to support the claims; and a judgement/outcome. If a new claim is made, a new event unfolds and positions can be filled by new/additional players (Boltanski, 1996). The discussion here, focuses on the claims made and use of affiliations to defend the claims. Examples from both cases are given in Tables 1 to 4, which highlight the transitions from one phase to the next. Details were taken from public documents which described the events in each case.

\section{Onset}

The onset phase is difficult to access because containment measures usually mean that detail about this phase is limited (Rayner \& Hoel, 1997). The details given in the onset phase are gleaned from later events, once the conflict breached containment.

Table 1: Sample Onset Events: David Jones and Café Vamp Cases

\begin{tabular}{lll}
\hline ONSET & David Jones 7.6.10 & $\begin{array}{l}\text { Café Vamp - suicide of Brodie } \\
\text { Panlock 2o.9.06 }\end{array}$ \\
\hline Denouncer & $\begin{array}{l}\text { Kristy Fraser-Kirk (KFK)- junior } \\
\text { publicist }\end{array}$ & $\begin{array}{l}\text { Coroner - details provided during } \\
\text { breach phase }\end{array}$ \\
\hline
\end{tabular}

Target

Kristy Fraser-Kirk- junior

Brodie Panlock 
publicist

\section{Persecutor/s Main claim}

\section{Resources for target Resources for persecutor}

\section{Judge Outcome}

Mark McInnes CEO

Female employee claimed that McInnes had sexually harassed her
Identities remain anonymous Male staff at Café Vamp including the manager who was in a relationship with Brodie had "aggressively" bullied her

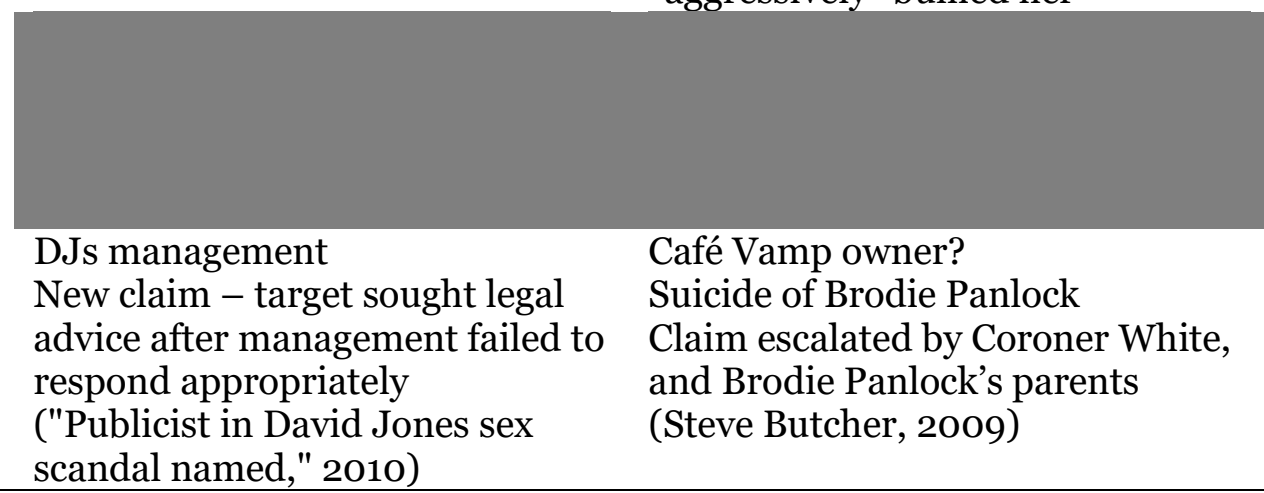

Source ("Publicist in David Jones sex (Steve Butcher, 2009)

\section{Breach of containment}

The breach of containment phase occurs when the dispute is escalated into the public domain. During this phase, a struggle ensues as the players attempt to defend their claims. For the organisational players, in particular, the imperative is to recontain the matter as quickly as possible to avoid damage to reputations and other financial penalties (Habiba, 2014). Identities of players are no longer suppressed or anonymous (Boltanski, 1996).

Table 2: Sample Breach of Containment Events: David Jones and Café Vamp Cases

\section{BREACH OF $\quad$ David Jones 3.8.10 $\quad$ Café Vamp 11.12.09 \\ CONTAINMENT}

Denouncer

Target

Persecutor/s

Main claim

$\underset{\substack{0 \\ 0 \\ 0}}{\sigma}$

\section{Lawyers for Kristy Fraser-Kirk} (KFK)

Kristy Fraser-Kirk - junior publicist

Mark McInnes- CEO +

David Jones chairman Robert

Savage; chief financial officer

Stephen Goddard and; new CEO

Paul Zahra (named as respondents)

That McInnes had sexually harassed Fraser Kirk and that the Board had known about this and had failed to act

Resources for target
KFK's parents and partner Chris Drew

Legal team-Harmers Workplace

\section{Coroner}

Brodie Panlock

Nicholas Smallwood, 26- manager of the cafe (relationship);

Rhys MacAlpine, 28; Gabriel Toomey, 23 (chef); Marc Luis Da Cruz (Cafe Vamp's owner);

(Inquest) The three male employees of Café Vamp pleaded guilty to treating Brodie Panlock in an "extremely aggressive and intimidating" manner in the workplace Ashley Cooper (friend) Nicola Wood (colleague/employee) 


\begin{tabular}{|c|c|c|}
\hline \multirow{4}{*}{$\begin{array}{l}\text { Resources for } \\
\text { persecutor }\end{array}$} & Lawyers & \multirow[b]{2}{*}{ Owner Café Vamp } \\
\hline & Mark McInnes; & \\
\hline & $\begin{array}{l}\text { pregnant girlfriend Lisa Kelly; } \\
\text { three senior David Jones -Paul }\end{array}$ & \\
\hline & Zahra as new CEO (effective & \\
\hline & immediately) & \\
\hline & -Robert Savage Chairman & \\
\hline & -Stephen Goddard- chief financial & \\
\hline & officer- & \\
\hline & managers; & \\
\hline & (DJs) company and its directors & \\
\hline & Board of DJs- & \\
\hline \multirow[t]{2}{*}{ Judge } & Federal Court, Sydney & Coroner \\
\hline & & WorkSafe \\
\hline \multirow[t]{6}{*}{ Outcome } & Fraser-Kirk seeking & Employees charged \\
\hline & $\begin{array}{l}\text { compensation from McInnes and } \\
\text { DJs }\end{array}$ & Owner da Cruz fined by WorkSafe \\
\hline & Complaint lodged with Human & Claims depersonalised and \\
\hline & Rights Commission & advanced as a social affair when \\
\hline & Hearing date set for 30.8 .10 & Premier John Brumby announced a \\
\hline & & (Adonis, 2010) \\
\hline Source & (Fife-Yeomans, 2010b; & (Butcher, 2009) \\
\hline & Huntington, 2010a) & \\
\hline
\end{tabular}

\section{Recontainment}

Even though Kristy Fraser-Kirk's legal team made several attempts to depersonalise the claims, e.g. by focusing on all women who may have been sexually harassed and stating that proceeds from the case would be donated to a charity as the focus was on cultural change (Funnell, 2010), they were unsuccessful and a decision was made to accept the settlement offered by DJs and McInnes' lawyers (David Jones, 2010). This recontained the affair and made it a private matter between the players (as for onset). The outcomes were superficial (changes to staff and policy) (see David Jones, 2012; Habiba, 2013b).

Table 3: Sample Recontainment Event: David Jones Case

\section{RECONTAINMENT David Jones 18.10.10}

Denouncer Lawyers for Kristy Fraser-Kirk

Target Kristy Fraser-Kirk

Persecutor/s DJs CEO Mark McInnes

Main claim A settlement agreement of $\$ 850000$ was reached

Resources for Harmers Workplace Lawyers

target

Ruth Medd - Chairwoman of Women On Boards

The Sex Discrimination Commissioner - Elizabeth Broderick

Fraser-Kirk's partner (Chris Drew)

Resources for Lawyers

persecutor

Asia Pacific Institute of Advanced Research (APIAR) DOI : 10.25275/apjabssv4i1ss1 

Judge
Federal Court and Australian
Human Rights Commission.

Outcome

Fraser-Kirk paid compensation, upon signing a confidentiality agreement and dismissed from position - moved to Singapore (Barlass, 2011)

McInnes resigned his position and was reemployed later as CEO of Premier Investments (Zappone, 2011)

Source (David Jones, 2010)

\section{Social Affair}

However, the Café Vamp case transformed to become a social affair, as collective players acted to depersonalise and generalise the claim to one of concern for all workers/employers. Table 4 highlights this shift. Even though legal players may be able to draw attention to the wider issues, players representing collectives, such as government and OHS officials, are needed to advance the claims and move the debate away from individuals and personalised/psychologised explanations (Boltanski, 1996).

Table 4: Sample Social Affair Event: Café Vamp Case

\section{SOCIAL AFFAIR Café Vamp 12.2.10}

\begin{tabular}{ll}
\hline Denouncer & Premier John Brumby/WorkSafe \\
Target & All workers \\
Persecutor/s & All workers \\
Main claim & The government would crack down on workplace bullying. A "blitz" on \\
Resources for & Victorian workplaces would be conducted by WorkSafe \\
target & Victorian Government; \\
& WorkSafe inspectors; \\
& Nat. Centre Against Bullying; \\
& HR; \\
& Victorian Premier John Brumby; \\
draft report of the Productivity Commission; & Stan Krpan, the acting executive director of WorkSafe Victoria; \\
Wesources for & Workplace Bullying Institute \\
Adversarial employers; & Insurance and medico-legal systems; \\
Bersecutor & Bystanders \\
Judge & Coroner \\
WorkSafe & Changes made to Victorian law - workplace bullying covered by \\
Outcome & stalking laws \\
& Jail terms introduced \\
Changes to law to account for workplace bullying claims proposed and \\
being introduced nationwide
\end{tabular}

Source

(Adonis, 2010) 


\section{Examining other factors that play a role using Bourdieu's field theory}

To expand upon the Boltanski analysis, Bourdieu's field theory which examines how players struggle within a field/subfield over a central stake (e.g. the safety and well-being of workers) using internal factors such as capital (economic, social-affiliations, cultural-education, experience/training, religion and class and symbolic-inferred power over others) and/or external factors such as government and OHS influences, to gain control(Bourdieu, 2004; Bourdieu \& Wacquant, 1992), was used to examine some aspects of each case in more detail. Two of these factors are discussed briefly here, namely historical factors (external)and affiliations (internal).

Analysis of historical factors in both cases revealed that the historical factors were absent in the Café Vamp case. However, in the David Jones case, it was revealed that both Fraser-Kirk and McInnes had previously been involved in similar conflicts. Fraser-Kirk had lodged a claim against a former work colleague (Moran \& Marcus, 2010) and McInnes had previously had claims of sexual harassment made about him (Fife-Yeomans, 2010a). Whilst these claims related to the protagonists and were personal in nature, they highlight the risk identified by Boltanski that claims that were not addressed fully had the ability to re-emerge at a later date (1996).

The Boltanski analysis also emphasised the importance of affiliations to the defence of claims. A closer examination of these affiliations reveals that the capital players hold is an important feature when attempting to influence the field and the struggle over the stake central to that field (e.g. the safety and well-being of workers) (Bourdieu, 2004; Bourdieu \& Wacquant, 1992).

In the David Jones case, Fraser-Kirk challenged the CEO and the Board of David Jones, both of whom held considerable capital, particularly symbolic power, over the field. As she had limited capital (as a junior publicist she had little experience and/time to accrue capital), it was important that she was affiliated with players whose capital would match that of her opponents and bring pressure to bear on the field. Despite some attempts by her legal team to depersonalise the case and attract the support of a collective, she failed to transform the case to one of general concern. A number of players with influence, including the Australian Sex Discrimination Commissioner, Elizabeth Broderick, made comment on the case after the settlement proceedings had begun (Huntington, 2010b), but the case did not reignite and gain the momentum that would have helped it to transform, even at this late stage. However, the Café Vamp case was transformed to become an issue of general concern (for the safety of workers) because Panlock's parents were able to garner the support of government (Victorian Premier John Brumby) and OHS (WorkSafe) officials who were able to bring pressure to bear on the case from outside of the field and influence control over the stake and workplace conditions.

\section{Discussion}

Organisational conflict continues to dominate as a serious problem for all stakeholders. Historically, personal accounts have come to dominate the discourse about organisational conflicts. However, whilst attention is focused on the psychological aspects of these disputes, resolutions that go beyond superficial measures are difficult to attain. This can result in ongoing costs (e.g. financial, reputational and psychological) for all involved. To expand the possibilities for better resolutions to and a deeper understanding of organisational conflicts, earlier interventions that consider not only the relations between the central players, but also other factors that may have contributed, especially during the onset phase of a dispute, need to take place. The emphasis of these interventions needs to incorporate broader strategies for examining contributory factors, including personal details, leading to more effective and lasting solutions. 


\section{References}

i. $\quad$ Adonis, J., 2010. This is exactly how you tackle workplace bullying. My Small Business.. [Online] Available at: ttp://blogs.smh.com.au/smallbusiness/workinprogress/2010/02/12/

workplacebully.html

ii. Barlass, T., 2011. Kristy Fraser-Kirk is back ... in Singapore. Sun Herald p. 3.. [Online] Available at:http://griffith.summon.serialssolutions.com/link/o/eLvHCXMwQ7QySSwPjIG VubmuCfh8VoTnH6mwdxNlkHNzDXH2OIUVmvEpOTnxwDoGPJ8IbDnwpekc2pNR7sW2aLnbGc1A gokAhospaQ

iii. Boltanski, L., 1996. Endless disputes from intimate injuries to public denunciations.. Working papers in networks and interpretation, 96(2), p. 32.

iv. Bourdieu, P., 1998. . The essence of neoliberalism: What is neoliberalism? A programme for destroying collective structures which may impede the pure market logic. [Online] Available at: http://mondediplo.com/1998/12/o8bourdieu

v. Bourdieu, P., 2004. The forms of capital. In: S. J. Ball, ed. The RoutledgeFalmer Reader in Sociology of Education. London, United Kingdom: RoutledgeFalmer. , pp. 15-29.

vi. Bourdieu, p. \& L.Wacquant, 1992. An invitation to reflexive sociology. Cambridge, London: Polity Press.

vii. Butcher, S., 2009. Brodie's torment. [Online] Available at: http://www.theage.com.au/national/brodies-torment-20091210-kmgr.html

viii. Butcher, S., 2009. Four men face charges over teen's suicide. The Age. [Online] Available at: http://kingsworkplacesolutions.com.au/articles/young-brodie-panlock.html

ix. Ehrlich, C., 1997. Human resource management: A changing script for a changing world. Human Resource Management, 36(1), p. 85.

x. Engman, C., 2003. Regulating the Psychosocial Issues in Changing Work Situations. Paper presented at the Australian OHS Regulation for the 21st Century, National Research Centre for Occupational Health and Safety Regulation \& National Occupational Health and Safety Commis. [Online] Available at: http://ohs.anu.edu.au/publications/pdf/wp\%2017\%20-\%20Engman.pdf

xi. Eurofound, 2009. Arbetsmiljolagen Work Environment Act. [Online] Available at: http://www.eurofound.europa.eu/emire/SWEDEN/ANCHOR-ARBETSMILJ-Ouml-

LAGENSE.htm

xii. $\quad$ Fife-Yeomans, J., 2010. Black and Decker day for ex-boss - Sex claims go back 20 years. The Daily Telegraph p. 7. [Online] Available at: http://griffith.summon.serialssolutions.com/link/o/ eLvHCXMwQ4wAkFgeAMtQM2Nd8GUtiL4 a4uyhCysz41NycuJBJ5KZm5qYmRga8olf5zp3 qS7V6PUoXdJlZNLAWjDKqs

xiii. $\quad$ Fife-Yeomans, J., 2010. Inside the David Jones sex scandal. The Daily Telegraph.. [Online] Available at: http://www.dailytelegraph.com.au/news/sydney-nsw/inside-the-david-jonessexscandal/story-e6freuzi-1225900260332

Funnell, N., 2010. Disaster at David Jones signals what's in store for corporate big boys. The Sydney Morning Herald. [Online] Available at: http://www.smh.com.au/federalpolitics/society-andculture/disaster-at-david-jones-signals-whats-in-store-for-corporate-bigboys-20100804-11fix.html

xv. Geelong Advertiser, 2010. Former David Jones boss returns to Australia ready to fight. [Online] Available at: $\underline{\mathrm{ttp}}$ ://global.factiva.com.libraryproxy.griffith.edu.au/redir/default.aspx?P=

Asia Pacific Institute of Advanced Research (APIAR) DOI : 10.25275/apjabssv4i1ss1 
xvi. $\quad$ sa\&an=GEEADV002 0100817e68gooook\&cat=a\&ep=ASE

xvii. George, S., 1999. A short history of neoliberalism. Paper presented at the Conference on Economic Sovereignty in a Globalising World. Bangkok, Conference on Economic Sovereignty in a Globalising World.

xviii. Habiba, P., 2013. Recontainment: Lessons to be learned from a public harassment case. Review of Social Studies, Law and Psychology, 7(3), pp. 61-69.

xix. Habiba, P., 2013. The difference between psychological and social affairs and the implications for key players. Mustang Journal of Business and Ethics, 5(11), pp. 93-104.

xx. Habiba, P., 2014. The containment of organisational and institutional disputes and scandals: Utilising a trading zone approach in the construction of the object to explore their hidden dimensions. (Doctor of Philosophy), Brisbane, Queensland, Australia: Griffith University.

xxi. Habiba, P., 2016. The Australian Defence Force Academy Skype sex scandal: Understanding the implications of containment. Armed Forces and Society, 1(22).

xxii. Hacking, I., 1986. Making up people. In: N. F. \&. D. E. W. T. C. Heller, ed. Reconstructing individualism: Autonomy, individuality and the self in Western thought . Stanford: Stanford University Press, pp. 222-236.

xxiii. Hacking, I., 2006. Making up people. London Review of Books, 28(16).

xxiv. Harvey, D., 1990. The condition of postmodernity: An enquiry into the origins of cultural change. Malden, MA, United States of America: Blackwell.

xxv. Harvey, D., 2005. A brief history of neoliberalism. Oxford, UK: Oxford University Press. .

xxvi. Hoel, H., Sheehan, M., Cooper, C. \& Einarsen, S., 2011. Organisational effects of workplace bullying. In: H. H. D. Z. \&. C. L. C. S. l. Einarsen, ed. Bullying and harassment in the workplace. Boca Raton, Florida, United States of America: CRC Press, pp. 129-148.

xxvii. $\quad$ Huntington, P., 2010. David Jones hit with harassment suit, s.l.: WWD, 200.

xxviii. Jones, D., 2010. David Jones reaches settlement on Fraser-Kirk litigation. [Online] Available at: http://www.davidjones.com.au/images/For-Investors/ASX-and- ediaReleases/2010/kfk

xxix. Jones, D., 2012. Code of ethics and conduct. [Online] Available at: http://www.davidjones.com.au/For- Investors//media/Files/Corporate/Investors\%20new\%20PDF/

xxx. $\quad$ Code\%20of\%20Ethics\%20and\%20Conduct \%20Website\%20May\%202012.ashx

xxxi. Khilawala, R., 2011. History of Human Resource Management.. [Online] Available at: http://www.buzzle.com/articles/history-of-human-resource-management.html

xxxii. Lécuyer, C., 2003. High-Tech Corporatism: Management-Employee Relations in U.S. Electronics Firms, 1920s-1966os. Enterprise \& Society, 4(3), p. 502.

xxxiii. $\quad$ Moran, J. \& Marcus, C., 2010. David Jones sexual harassment accuser Kristy FraserKirk has a past case. theTelegraph.. [Online] Available at: http://www.dailytelegraph.com.au/news/david-jonessexual-harassment-accuser-kristy-fraserkirk-has-a-past-case/story-e6frewto-1225902509986

N $\underset{\substack{\infty \\ \sigma}}{\infty} \times x x i v$.

Nine MSN, 2010. Publicist in David Jones sex scandal named. [Online] Available at: http://news.ninemsn.com.au/national/1073275/publicist-in-david-jones-sex-scandalnamed 
xxxv. Rayner, C. \& Hoel, H., 1997. A summary review of literature relating to workplace bullying.. Journal of Community and Applied Social Psychology, 7(3), pp. 181-191.

xxxvi. Zappone, C., 2011. Ex-DJs boss McInnes back in retail business smh.com.au.. [Online] Available at: http://m.smh.com.au/business/exdjs-boss-mcinnes-back-in-retail-business201103251c92k.html?page $=2$ 